\title{
EL INSTITUTO PEDAGÓGICO: MISCELÁNEAS DE ESTUDIOS PEDAGÓGICOS
}

\author{
Valentín Letelier; Prólogo De Roberto Munizaga. \\ SANTIAGO DE CHILE: INSTITUTO CULTURAL GERMANO \\ CHILENO, 1940. (NASCIMIENTO). \\ (Fragmento)
}




\section{INSTITUTO PEDAGÓGICO, VALENTÍN LETELIER.}

\section{Sus precursores (a)}

Es cosa de todos sabida que en la mecánica los efectos de las fuerzas se siguen desarrollando, por un tiempo más o menos largo, aun después que ellas dejan de actuar; que cuando uno toma distancia para dar un salto, el impulso le lleva hasta más allá del punto de mira; y que para detener el tren en una estación, es menester cortar el vapor tanto más lejos cuanto mayor es la rapidez con que viene.

En el orden moral sucede exactamente lo mismo. Un moralista predica un ideal para reformar la sociedad y los discípulos que han recibido el impulso del espíritu nuevo siguen haciendo y reclamando reformas largo tiempo después de haberse realizado el ideal del maestro. Un fanático azuza a sus prosélitos contra el predicador de una secta antagónica, y ellos se abalanzan a la manera de una ola ciega, incontenible y devastadora, y no sólo impiden al adversario ejercer su derecho, sino que saquean e incendian las propiedades de los disidentes y siembran en todos los hogares el espanto, la deshonra y la muerte.

Hechos son éstos cuya trascendencia está al alcance del más vulgar observador, que de ordinario no llaman la atención por causa de su misma simplicidad y que suelen olvidarse cuando sería más conveniente recordarlos.

Es evidente, verbigracia, que convendría sobremanera tenerlos presentes en los momentos en que una revolución acaba de triunfar, porque de otra suerte nos dejamos arrastrar por el movimiento revolucionario hasta después de realizados los propósitos del primer impulso.

En la política sucede lo mismo que en el orden físico, lo mismo que en el orden moral: los efectos se siguen desarrollando hasta después de haber cesado las causas; el movimiento continúa largo tiempo después de suspendido el impulso; o en otros términos, las revoluciones tanto como las reacciones, se acometen con un propósito determinado, y una vez que lo realizan, siguen desarrollándose indefinidamente con propósitos diferentes.

No digo yo que esto sea siempre malo; hay, sin duda, ocasiones políticas en que conviene aprovechar el impulso de los acontecimientos para hacer en bien del pueblo más de lo que se había pensado a los principios. Pero si digo que nunca es propio de seres racionales obrar sin discernimiento y dejarse arrastrar pasivamente por la corriente general. Como agente moral, el primero de los deberes del hombre es el 
de elegir por sí mismo el camino que debe seguir, las obras a que debe contribuir, las tareas en que debe cooperar.

Muy a menudo me he repetido estas observaciones en los últimos meses con motivo de los sucesos ocurridos después de 1891, porque merced al auge obtenido en las pasadas elecciones, los conservadores han intentado torcer el rumbo de la revolución para hacerla servir al triunfo de la reacción y muchos liberales se han prestado a servirles de cooperadores porque a ello se creen obligados en nombre del propósito con que se unieron.

¿Con qué propósito se alzó en armas la República contra el gobierno de Balmaceda? Con sólo dos propósitos fundamentales:

$1^{\circ}$.- Para devolver al pueblo sus derechos electorales; y

$2^{\circ}$.- Para derrocar la Dictadura, que virtualmente se estableció el día en que el Presidente declaró su resolución de seguir gobernando con absoluta prescindencia del Congreso.

No hicimos, por consiguiente, la revolución ni para substituir la intervención de los intendentes por la de los párrocos, ni para que gobernaran revueltos, partidos de opuestos ideales, ni para derribar la política liberal, ni para abolir las instituciones docentes del Estado.

En la práctica, sin embargo, el impulso que todos recibimos del Congreso para alzarnos contra la Dictadura, sigue obrando después de haberla derrocado; y una vez derribado Balmaceda como Dictador, muchos querrían seguir adelante y destruir a ciegas aun lo que hizo como Presidente. En otros términos, la revolución terminó, pero el espíritu revolucionario subsiste.

Si no estoy equivocado, esta circunstancia explica en parte los ataques que algunos liberales dirigen al presente contra una de las más notables instituciones del servicio docente de la República, cual es el Instituto Pedagógico. Combatido de frente y de antiguo por los conservadores, porque su política les impone el deber de impugnar todas las instituciones docentes del Estado, aquel establecimiento ve formar filas entre sus adversarios a muchos liberales que querrían borrar hasta el último vestigio de la administración derrocada.

Sin conocer la razón de su existencia, ni sus antecedentes, ni sus orígenes, ni a sus verdaderos autores, esos liberales lo reputan idea personal de Balmaceda y obra exclusiva de Bañados, y se imaginan que su erección respondió al propósito de ensanchar el aparato externo de aquella administración rumbosa y despilfarradora.

En estas condiciones, me ha parecido oportuno recordar los antecedentes del Instituto Pedagógico y exponer las razones que justifican su creación. Relatando su historia fidedigna, se verá que de entre los radicales y los liberales, cooperaron a su establecimiento, con más o menos empeño y perseverancia, cuantos estuvieron en situación de prestarle la ayuda de sus esfuerzos. Acaso esta exposición será parte a 
contener los ímpetus de aquellos que se imaginan que hicimos la revolución para destruir, siendo así que en 1890 ningún constitucional habló de otra cosa que de la necesidad de restablecer el juego normal de las instituciones nacionales.

¿Cuáles son, pues, los antecedentes del Instituto Pedagógico? ¿Cuál su razón de ser? ¿Quiénes sus fundadores?

Por primera vez, que yo sepa, se habló en Chile de la necesidad de dar una educación especial a los aspirantes de profesorado hacia el año 1842.

En aquella fecha, don Manuel Montt acababa de tomar a su cargo el Ministerio de Instrucción Pública, don Antonio Varas acababa de sucederle en el rectorado del Instituto Nacional, y hacía pocos años que don Ignacio Domeyko había ingresado en el profesorado del liceo de La Serena.

Domeyko era entonces un joven que después de haber recorrido una gran parte de Europa proscrito de su patria, y haber escuchado en París las lecciones de insignes maestros, podía dedicar al servicio de la República, no sólo un caudal considerable de ciencia, sino también ideas nuevas y avanzadas sobre la organización de la enseñanza nacional.

Así lo comprendió el Gobierno de aquella época, el cual, junto con trasladarle a Santiago para dar campo más vasto al ejercicio de sus facultades didácticas, le pidió un informe sobre las reformas que a su juicio se podrían introducir en el servicio de instrucción pública.

Domeyko expidió en breve tiempo su informe, y muchas de las medidas que propuso fueron adoptadas en el acto o lo han sido más tarde como base de la enseñanza nacional. Como quiera que hasta entonces las asignaturas del plan de estudios no estuvieran clasificadas ni jerarquizadas, el sabio polaco propuso que se dividiera el curso de humanidades en seis clases correspondientes a otros tantos años; y que en ellas se enseñaran simultáneamente desde la primera hasta la última de las matemáticas, la historia, las lenguas y las ciencias naturales. Sin usar la palabra, cuyo introductor en la pedagogía nacional creo haber sido yo, Domeyko proponía un verdadero plan concéntrico de estudios. Suspende el ánimo encontrar en un documento fechado ha cincuenta años, ideas sobre instrucción que hoy mismo no se profesan en Chile sino por los más adelantados de nuestros educacionistas y que los conservadores repudian sin examen porque los suponen de importación radical.

Carecería de objeto repetir aquí en detalle lo que mi amigo don Domingo Amunátegui Solar ha relatado tan donosamente en Los primeros años del Instituto Nacional, obra que en realidad comprende la historia entera de la instrucción secundaria durante la primera época. Pero sí es indispensable rastrear los orígenes de la institución pedagógica que tan encarnizadamente se combate.

En el mismo informe proponía Domeyko que se organizara una pequeña escuela normal de profesores, semejante a la que él había visto funcionar en París bajo la 
mano del eminente filósofo Víctor Cousin. Domeyko no sólo insinuaba la idea sino que explanaba, siquiera fuese en términos concisos, un proyecto perfectamente realizable. Proponía que de las becas fundadas en el Instituto Nacional por el Gobierno liberal de 1829 se reservaran unas diez para sendos alumnos de la Escuela Normal; que de ellas se dieran dos a cada uno de los cinco colegios de instrucción secundaria que entonces había en la República: que los becarios se establecieran en un departamento especial del Instituto Nacional después de concluir sus estudios en los liceos, que aquí repasaran durante dos años los ramos que habían estudiado en las provincias; que en seguida estudiaran en la Universidad dos años más aquellas ciencias a cuya enseñanza mostrara cada uno más afición: y, en fin, que durante este cuadrienio, se ejercitaran en la didáctica bajo la dirección de un pedagogo.

Como se ve, era éste un plan completo, práctico, realizable, muy adecuado a las necesidades de la instrucción y muy poco dispendioso. Patrocinado con entusiasmo por el rector del Instituto Nacional, el Gobierno dispuso el 8 de febrero de 1843 que tres de las becas de aquel establecimiento se reservasen para jóvenes que aspiraran a servir de profesores en el liceo de Concepción, y otras tantas para los que aspirasen a servir en el de Coquimbo.

Empero, la nueva institución no rindió los frutos que de ella se esperaba. Según el plan de Domeyko, los estudios pedagógicos que habían de habilitar para el ejercicio del profesorado eran más o menos tan largos como los que habilitaban para el desempeño de las otras carreras liberales; y en estas condiciones, no había alumnos sobresalientes que quisieran comprometerse a abrazar una profesión tan mal remunerada cuando en el mismo lapso podían prepararse para seguir otra más lucrativa.

A este defecto capital de la nueva institución, se agregó el de no haberse dictado disposición para hacer que los becarios desarrollaran más sus conocimientos ni para que se ejercitaran en el arte de la enseñanza. Concretándose a repartir seis y ocho becas entre los alumnos más distinguidos, el Gobierno podía formar bachilleratos más o menos ilustrados, pero no verdaderos profesores. La necesidad de formar el personal docente quedó subsistente.

En 1863, asumió la dirección del Instituto Nacional el más eminente de los educacionistas chilenos, el que habiendo escrito menos sobre la teoría de la educación ha hecho más en la práctica por el desarrollo de la enseñanza secundarias: todos adivinan que aludo al sabio maestro don Diego Barros Arana.

Don Diego Barros Arana, que había viajado, que había observado y estudiado, que tenía un ideal nuevo de la educación notó desde el primer momento la deficiencia del profesorado y la falta de una institución que amaestrase aspirantes. Con ser el Instituto Nacional el establecimiento de instrucción secundaria dotado de mejores profesores, la enseñanza dejaba mucho que desear. Funcionaban allí (es verdad) 
literatos y humanistas distinguidísimos: Vendel-Heyl, Lobeck, Pizarro, Amunátegui, etc., lucían en las letras una erudición realmente notable; pero la didáctica de cada uno de ellos se resentía de vicios que se habría podido borrar con una ligera tintura de pedagogía. En todo caso, era notorio que no había a donde recurrir para llenar las vacantes con aspirantes idóneos. Lo único que se podía hacer era esconderlas o bien, a uno u otro extranjero ilustre que llegaba a establecerse en Chile, o bien a jóvenes nacionales que después de haber hecho una carrera más o menos brillante como alumnos, mostraban algún amor al estudio y a la enseñanza.

Pero eso no bastaba. Los buenos profesores subían, por lo general, a las catedrales con poca preparación científica y con ninguna preparación pedagógica. Su enseñanza era deficiente en cantidad e imperfecta en calidad. Para mejorarla, era menester que el profesor aumentara sus conocimientos y se ejercitase en el arte de trasmitirlos a un auditorio infantil.

Cuantos nos educamos en el Instituto Nacional (seguí yo sus cursos de 1867 a 1871) recordamos claramente el empeño inflexible y perseverante que, no obstante su ingénita bondad, ponía el señor Barros Arana para extirpar las prácticas rutinarias de una enseñanza que, por torpe, no sabía hablar que a la memoria de los educandos, dejando en completo olvido la educación de las demás facultades. Sus frecuentes visitas a las clases (prácticas abandonadas por sus sucesores), su manera de interrogar, de enseñar y de examinar, los textos que adopto y los que compuso, y sobre todo, sus insistentes consejos a profesores y alumnos, se dirigían a demostrar que un maestro no es un ministro de fe llamado a certificar un hecho, el aprendizaje mecánico de la lección, sino que es un agente activo que sabe interesar, excitar y guiar las inteligencias educandas para hacerlas que desarrollen sus conocimientos por sus propios esfuerzos. Varios de los profesores más antiguos del Instituto Nacional le secundaron abnegadamente en su empeño, y algunos de los que se formaron bajo la inspiración de su consejo y de su ejemplo cuentan hasta hoy mismo entre aquellos que más honra y lustre dan al profesorado del Nacional.

Pero el señor Barros Arana no podía sentirse satisfecho con tener colaboradores que se hacían verdaderos maestros solo a costa de la enseñanza, años después de recibir la investidura del profesorado; y para remediar el mal, propuso al Gobierno que aplicase algunas becas del Instituto Nacional a la formación de un cuerpo de repetidores; y que al efecto diera unas a los alumnos más distinguidos del curso de humanidades, y otras a los más distinguidos de matemáticas.

En compensación de las becas, ellos debían suplir a los inspectores reemplazar a los profesores y dar lecciones privadas a los alumnos que las hubieran menester. Prestarían así servicios que en gran parte compensarían los sacrificios del Estado, y junto con prestarlos, adquirirían a la larga una preparación pedagógica, si quiera fuese deficiente, para ocupar las vacantes del profesorado. El Gobierno defirió las 
indicaciones del señor Barros Arana, y por decreto fecho el 5 de octubre de 1863 aprobó un Reglamento para el Instituto Nacional, cuyo título undécimo instituía las becas de repetidores.

Tan cierto como es que la enseñanza nacional mejoró sobremanera bajo el impulso de Don Diego Barros Arana, lo es también que la institución de los repetidores alcanzó a dar frutos de no escasa valía. Muchos de ellos adquirieron en tal carácter esos hábitos de orden, disciplina y exactitud que el sabio rector imponía a sus subalternos y que más tarde llevaron ellos consigo a los liceos como empleados administrativos. Otros ingresaron en el profesorado del Instituto, después de ensayos que permitieron aquilatar sus aptitudes para desempeñar las delicadas funciones de la enseñanza. Perfeccionada la institución, puestos los repetidores bajo la mano de un pedagogo contratado especialmente en Alemania, ella habría servido por mucho tiempo de fuente para renovar el personal entero de aquel establecimiento.

Sin embargo, ni la institución duró largos años ni podía suplir por completo la falta de un seminario pedagógico. Hacía poco que la reacción clerical había quitado (1873) a don Diego Barros Arana la dirección del Instituto Nacional, cuando fueron suprimidas las becas de repetidores con el fin de hacer encomias en el presupuesto. Si se las hubiera conservado, ya se habría sentido la doble necesidad de aumentar su número a fin de proveer a las vacantes de todo el profesorado nacional y de organizar mejor la institución, a fin de amaestrar a los becarios en el arte de la enseñanza.

Tal era en Chile el estado de las cosas cuando en 1885 propuse al Supremo Gobierno la fundación de un seminario de profesores.

\section{NECESIDAD DEL INSTITUTO PEDAGÓGICO}

La necesidad de preparar especialmente a los aspirantes del profesorado no se ha hecho sentir con fuerza sino en nuestro siglo por dos causas principales: $1^{\circ}$ porque la función docente estaba antes encomendada de una manera casi exclusiva al cuerpo sacerdotal de cada nación; y $2^{\circ}$ porque reducida la enseñanza a la tarea mecánica de dar y recibir lecciones de memoria, no se necesitaba preparación alguna para ocupar una cátedra de profesor. En este punto que puse de manifiesto en mi estudio precedente sobre La Escuela Normal Superior de París.

En nuestro siglo han cambiado radicalmente las cosas porque, al reasumir en sus manos la prerrogativa de la enseñanza, el Estado ha creado la necesidad de formar un personal docente laico: y al introducir las ciencias naturales en los planes de estudio, ha creado la necesidad de profesarlas con arreglo o métodos más o menos complicados, cuyo manejo no se aprende por revelación. Así se explica, 
mejor que por el falso prurito de la imitación, la significativa circunstancia de que todos los pedagogos, todos los educacionistas, sin distinción de secta, escuelas ni partidos, reconozcan la necesidad de la educación pedagógica.

Donde se han fundado instituto consagrados a este objeto, las autoridades docentes hacen cuanto les es dable por conservarlos y mejorarlos; y donde no los hay, la aspiración más insistente de los pedagogos es que se funde alguno (b).

No cambia de naturaleza el arte de la enseñanza cuando se pasa de un grado inferior a uno superior: y si todos convienen en que se debe fundar institutos para formar perceptores de escuela, no se comprende por qué no habían de convenir también en la necesidad de fundar otros para formar profesores de liceo. "Ya la necesidad de escuelas normales para la instrucción primaria (decía Cousin en 1836) penetra en todos los espíritus; y no dudo que antes de mucho reconocerán que esta misma necesidad existe en la instrucción secundaria, todos aquellos que se unieran seriamente de la organización de la enseñanza pública" (c ).

Todo arte, todo oficio, toda profesión requiere una preparación especial del que se consagra a su ejercicio; y de ordinario la aptitud educada sistemáticamente rinde en menos tiempo mejores frutos que la simple habilidad empírica. ¿Por qué la enseñanza, que es una de las artes más completas, podría prescindir con ventajas de esta educación previa?

Pocas personas de razón habrá capaces de sostener que no se necesita estudiar para ser abogado, o para ser médico, o para ser arquitecto. Se sostiene la necesidad de la educación jurídica, médica o arquitectónica aun cuando se sabe que sin adquirirla se forman tinterillos que defienden, charlatanes que curan y constructores que edifican. ¿Por qué, pues, se habría de dejar eternamente la enseñanza en manos de empíricos que toman lecciones a libro abierto?

Nadie ignora que en la enseñanza, como en todas las artes, echando a perder se aprende: que si un profesor inepto pone empeño y estudia la pedagogía, y ensaya métodos, y aprende el manejo de instrumentos útiles y aparatos, puede hacerse a la larga verdadero maestro, y que mediante ensayos y tanteos puede adquirir por si mismo después de algunos años una educación pedagógica completa. Agregaré que por estos medios la han adquirido algunos profesores nacionales que no la tenían en el acto de recibir la investidura del magisterio.

Pero prescindiendo de que son muy pocos los que así proceden, lo importante es determinar si los aspirantes del profesorado no deben educar sus aptitudes antes de recibir los nombramientos; o en otros términos, si no se debe fundar un seminario pedagógico de maestros, con el objeto de impedir que ellos vayan a formarse por sí mismos en los liceos a costa de las primeras generaciones escolares que caen en sus manos. 
En Chile es creencia general que cualquier ingeniero puede hacer un buen profesor de matemáticas, que todo médico es competente para enseñar las ciencias naturales y que la enseñanza de las humanidades se pone en buenas manos cuando se la encomienda a los abogados. Es este un gravísimo error, porque lo más propio para aquilatar la idoneidad de un profesor no es su saber, es su didáctica. Muy a menudo grandes sabios han escollado en las enseñanzas por falta de preparación pedagógicas y no hay inconveniente para que el más renombrado literato quede en ridículo al dar la primera lección de retorica. Si es verdad que no puede ser gran profesor el que no posee mucha ciencia, ello es que pierde menos el que disminuye sus conocimientos que el que desmejora sus métodos.

No hay arte más delicada, más compleja, más subordinada al conocimiento de la psicología que el arte de la enseñanza.

El buen profesor es aquel que, sin dejar de enseñar a todos sus alumnos en momentos alguno de la clase, instruye a cada uno de una manera especial. Sostener que se puede prescindir de la preparación pedagógica porque lo más de los profesores funcionan sin haberla adquirido, tanto vale como sostener que se puede ser pintor sin estudiar la teoría de los colores porque los pastores remedan toscamente las aves y las flores sin haber estudiado cosa alguna. Es un absurdo (dice Alcántara García) creer que la inspiración del momento o la simple vocación bastan para suplir esta preparación.

La inspiración y la vocación son estériles de ordinario cuando no la ilustran, fecundan y dirigen los conocimientos teóricos y prácticos del arte de educar (d).

Y ello se comprende.

Aun cuando algunos nazcan con vocación para la enseñanza, ninguno nace conociendo el arte de enseñar. La vocación es a lo más una predisposición o si se quiere, una aptitud natural. Para utilizarla, es menester educarla.

La forma de las interrogaciones, el giro de los diálogos, la exposición del asunto, el (...) de los instrumentos, el arte de interesar la atención de los alumnos, los resortes que se deben tocar para hacerles tomar parte activa en el estudio, el empleo de los métodos de demostración, observación, experimentación, clasificación, etc., en una palabra, el arte de desarrollar el espíritu y la personalidad del alumno, el arte de educarle instruyéndole, este arte supremo no se tiene si no se adquiere. "Si hay algo que no se puede improvisar en la enseñanza, dice Laprade, es el profesorado (e)".

La preparación perfecta del maestro supone, pues, justamente la adquisición de un caudal considerable de conocimientos y la del arte de trasmitirlos en forma didáctica. Pero mientras en la escuela el preceptor suele tener educación pedagógica sin instrucción científica, en el liceo el profesor suele tener instrucción científica sin educación pedagógica. En uno y otro caso, la preparación es deficiente porque 
el uno conoce el arte, pero no posee la ciencia; y el otro posee la ciencia pero no conoce el arte.

Esto no se ve en Suiza.

"Los aspirantes del profesorado, dice Dreyfus Brisac, están allí obligados a seguir cursos y conferencias teóricas y prácticas sobre la educación en general y sobre el método que se debe emplear en la enseñanza de la historia, de la filosofía, de las ciencias naturales. Trabajos escritos, exposiciones orales, discusiones, corrección de deberes, lecciones dadas en presencia de los profesores y de los camaradas: todos estos ejercicios se practican con el fin indicado. La pedagogía es a la vez enseñada como ciencia y practicada como arte. No se cree en Suiza, como en nuestro país. Que el arte de la enseñanza se deba aprender a fuerzas de tanteos, a la manera de una persona que se instruyera en el arte de curar matando enfermos.

La opinión común es que el profesor de liceo, tanto como el preceptor de escuela, no solo debe poseer a fondo el asunto de su asignatura, sino que antes de tomar a su cargo la enseñanza debe hacer indispensablemente un aprendizaje especial, iniciarse en el conocimiento de los mejores métodos didácticos, ejercitarse de una manera sistemática en el arte de la pedagogía" (f).

Lo mismo que en Suiza se procede actualmente en Francia, en Austria y sobre todo en Alemania. En todas las naciones más cultas de Europa, se ha comprendido que para dar una buena enseñanza se necesita tener un buen profesorado, y que para tener un buen profesorado es menester prepararlo en institutos especiales.

El desarrollo de la cultura no fue nunca fruto de generación espontánea. Fue siempre obra del esfuerzo inteligente y perseverante.

Como quiera que en Chile no hayamos existido preparación alguna de los aspirantes al profesorado la instrucción secundaria se ha mantenido lógicamente en un deplorable estado de atraso, porque no habiéndose amaestrado un personal docente ¿Cómo habría podido mejorar la enseñanza?

Profesores de instrucción secundaria tenemos como cuatrocientos, instituidos por obra y gracia de los nombramientos gubernativos; pero profesores que enseñen y eduquen, profesores que no se limiten a dar y tomar a libros abierto como lección el texto sacramental de un manual, profesores que se curen menos de recargar la memoria que de cultivar las facultades activas de cada educando; profesores que empleen en su enseñanza el método inductivo para hacer del estudio lo que debe ser, esto es, el arte de investigar; profesores tales hemos contado muy pocos hasta la renovación del arte pedagógico emprendida en los últimos años.

En los más de los liceos, el material de enseñanza objetiva permanecía embalado años y años o se le desembalaba para dejarlo enmohecer porque los profesores no sabían cómo utilizarlo. Los alumnos llegaban al término del curso sin haber presenciado un experimento, sin haber practicado ejercicio alguno, recargada la 
memoria con una suma abrumadora de reglas, definiciones y fórmulas. En las clases de castellano (salvando siempre al Instituto Nacional y a dos o tres liceos) no se les hacía escribir cartas, ni leer trozos de Cervantes, ni aprender estrofas de Quintana, ni traducir páginas del francés, ni componer relatos, ni construir raíces. En las de geografía, no se les enseñaba a formar croquis de la ciudad o del Estado, ni a trabajar líneas del ferrocarril o de las cordilleras, ni a orientarse en una serranía ni a seguir el itinerario de los vapores, ni a diseñar histórica y geográficamente los caminos territoriales de cada nación. Y en las ciencias física y naturales, no se les enseñaba a manejar los instrumentos, ni a formar herbarios, ni a clasificar especies, ni a comprobar experimentablemente las leyes, ni a observar nada. ¡El manual! jel manual! Era el principio y el término de la enseñanza; y consiguientemente, lucían más los alumnos de buena memoria que los de buena razón.

\section{ORÍGENES DEL INSTITUTO PEDAGÓGICO}

Cuando el 4 de enero de 1882 zarpé de Valparaíso con rumbo a Europa, conocía el estado deplorable de la instrucción pública en Chile, y llevaba en mí el propósito perfectamente madurado de estudiar en Alemania las reformas que podríamos hacer para mejorarla (g).

Por necesidad y por afición, había yo vivido consagrado a la enseñanza desde la adolescencia, y en el desempeño de mis funciones había notado y estudiado la deficiencia del profesorado y los vicios de sus métodos didácticos.

Siempre creía que el desarrollo de la cultura de cada pueblo está vinculado principalmente a su sistema de educación nacional; y por lo mismo, juzgaba que muchos de los defectos del carácter chileno, y las preocupaciones y errores absurdos de nuestro intelecto se debían achacar en primer término a la naturaleza y a la forma de la enseñanza pública. ¿Por qué no se ha difundido más el amor al estudio si no es porque la escuela lo extingue en germen, dando una enseñanza agobiadora, mecánica y repulsiva? ¿Por qué aparece atrofiado el intelecto nacional si no es porque la enseñanza descuida el cultivo de las facultades activas del espíritu? ¿Por qué el chileno, con una inteligencia más viva, se muestra más incapaz de las investigaciones científicas si no es porque sus maestros desatienden el deber de darle métodos, inclinaciones y rumbos?

Estas eran las reflexiones a que iba yo entregado mientras me acercaba al país que hasta ahora se distingue por la incontestable superioridad de su organización docente. A la verdad, no me daba cuenta de las causas del mal, aun cuando notaba con toda claridad el mal mismo. No conocía todavía más didáctica que la que había visto aplicada por los profesores nacionales, ni comprendía que fuese necesario dar 
a los aspirantes más preparación que la científica. Inspirado por alguna expresión tan desdeñosa como injustificada de Augusto Comte, creía que la pedagogía era un simple tejido de sutilezas metafísicas, y me parecía que con un poco de amor al estudio cualquier bachiller en humanidades podía hacerse eximio maestro en letras y en ciencia.

Rara vez puede el hombre emanciparse del medio ambiente, y si yo discurría de manera tan errónea, es porque los mismos errores corrían como verdades de fe en todos los institutos docentes de la República. En vez de imputarse nuestra atrofia mental a la instrucción viciosa que recibíamos, la imputábamos al coloniaje, a la raza o cualquiera otra causa extraña.

Muchos sostenían en principio que los preceptos de la pedagogía alemana eran inaplicables en Chile, y para esos, la enseñanza mecánica era la única adaptable a la índole del espíritu nacional.

Por fortuna, estos errores se desvanecieron de mi espíritu a poco de instalarme en Berlín. Como secretario de Legación obtuve franquicias especiales para visitar los establecimientos de instrucción pública; y asistiendo días y días a las escuelas, a los gimnasios, a los seminarios pedagógicos, a la Universidad, unas veces solo, otras acompañado de mi amigo Claudio Matte; interrogando a profesores y preceptores, observándolos en el acto de desempeñar sus funciones; me persuadí de que Alemania había creado, a fuerza de perseverancia y de estudios, una ciencia y un arte antes desconocidos, de aplicación y utilidad universal, el arte y la ciencia de la pedagogía.

A la verdad, no creo yo que sea menester asimilarse todas las materias de la pedagogía alemana para hacerse buen maestro. Evidentemente, huelgan en las obras pedagógicas de Alemania disquisiciones metafísicas de psicología subjetiva y de lógica aristotélica que no se hermanan bien con las nociones experimentales y que para el efecto de aprender el arte de la enseñanza, da lo mismo estudiarlas a fondo o no preocuparse de ellas.

Así y todo, es un honor que no se disputa a la nación germánica el de haber convertido la enseñanza en un arte técnico y el haberla fundado en principios científicos de universal aplicación. Cuando pensadores eminentes de otros pueblos creían ver en la pedagogía una creación sin base positiva, los maestros alemanes se ocupaban en formarla pieza a pieza con una paciencia infinita, haciendo mil ensayos, tanteando mil procedimientos, aprovechando la más nimia observación de la práctica diaria, hasta llegar en menos de medio siglo a cambiar la índole metafísica que juzgaba característica del intelecto germánico, a convertir todo estudio en una tarea de investigación, substituyendo la vía deductiva por la inductiva, y a establecer los principios teóricos de la enseñanza racional. Esto es lo que hay de realmente grande en el sistema docente de Alemania; esto es lo que hace aparecer a los pensadores germánicos de la segunda mitad del siglo como representantes genuinos 
de la ciencia, y esto lo que yo juzgué que se podría hacer en Chile para promover un desarrollo semejante en el intelecto nacional.

Movido por este propósito, cuando estudiaba el servicio de la enseñanza de Berlín, presté particular atención a los institutos que tenían por objeto formar el personal docente de la Prusia. Cuál es el secreto de la excelencia de la enseñanza germánica, era lo que yo me proponía averiguar. Para mí, que creo en la perfectibilidad de todas las sociedades humanas, es una simpleza metafísica atribuir a virtudes de tal o cual raza los adelantamientos que estos o aquellos pueblos han hecho, sea en la instrucción, sea en cualquier otro orden de la actividad. Dondequiera que se estudien las causas reales del desarrollo de la cultura, se llega invariablemente a una misma conclusión, a saber, que el progreso es obra del esfuerzo humano; que todos los pueblos pueden adelantar, porque todos pueden trabajar; y que no hay terreno que no produzca frutos cuando se le abona, se le riega, se le calienta y se le ilumina.

En el extenso informe que compuse, auxiliado por la inteligente colaboración de mi amigo Claudio Matte (i), consagré numerosas páginas a exponer la generación del profesorado de los gimnasios y de las escuelas reales. Hice ver allí que no son las virtudes ocultas de la raza que es la sabia organización del servicio docente lo que garantiza a los Estados alemanes la idoneidad, la suficiencia y la moralidad de sus profesorados. Baste saber que la pedagogía se enseña como ciencia en sus veinte universidades, y que además en numerosos institutos anexos a ellas se amaestran prácticamente los aspirantes del profesorado. Cualquiera otro pueblo puede llegar con esfuerzos parecidos a obtener frutos semejantes. Por eso, en la nota con que presenté al jefe de la Legación el informe aludido, insistí de una manera particular en la necesidad de exigir una preparación pedagógica a los que ambicionan ocupar un puesto cualquiera en el servicio de la instrucción pública.

Por de pronto, pareció que estas ideas habían caído en tierra estéril y que antes que de ellas cosecharíamos frutos de palmas nuevas, nadie se preocupó de estudiarlas. Estaba entonces la República comprometida en aquella ardentísima lucha de 1885, cuyo desenlace fue el triunfo de la candidatura de Balmaceda. No era coyuntura aquella para pensar en una labor administrativa, nueva y compleja.

Sin embargo, la semilla germinó mucho antes de lo que era de esperar. Excitado por el patriótico anhelo de mejorar toda la administración pública con que empieza sus funciones cada Gobierno, el de Balmaceda se propuso reconstruir las bases del servicio de instrucción secundaria. Apenas inaugurado el nuevo Gobierno, con fecha 8 de noviembre de 1886, el Ministro de Instrucción Pública, que lo era don Pedro Montt, presentó al Consejo del ramo un proyecto que contenía un plan de estudios, un plan de sueldos y las bases para instituir una escuela normal de profesores. 
"Es necesario (decía el señor Montt) que los profesores sepan no solo el ramo que deben enseñar, sino también la manera de enseñarlo, y que conozcan y apliquen los mejores métodos". Con este objetivo, proponía la fundación de un instituto donde solo podrían ingresar jóvenes que fuesen bachilleres en humanidades y donde habría cuatro clases; una de pedagogía, filosofía e historia; otra de filología, otra de matemáticas y otra de ciencias naturales. "El curso duraría cuatro semestres; durante los tres primeros, seguirían todos los alumnos las cuatro clases indiadas y harían ejercicios prácticos en el Instituto Nacional, y al fin de ellos rendirían un examen general. El cuarto semestre se destinaría exclusivamente a preparar a cada alumno, teórica y prácticamente, en el ramo que debiera enseñar más tarde; y rendido el correspondiente examen especial teórico práctico, recibiría el alumno un título que lo habilitaría para ser profesor o de historia, o de idiomas, o de matemáticas, o de ciencias naturales".

En cuanto a la organización administrativa, el señor Montt renovaba la idea del señor Domeyko y quería que la nueva escuela normal se estableciera como un anexo del Instituto Nacional. Al efecto, proponía que se fundaran en dicho establecimiento unas veinte becas para otros tantos aspirantes del profesorado y que los becarios quedaran obligados a suplir las faltas y ausencias de los inspectores y de los profesores.

En sus líneas generales no es dudoso que el proyecto del señor Montt hubiera obtenido la aprobación del Consejo de Instrucción Pública si la caída subsecuente del Ministerio, ocasionada por el fracaso de la candidatura del señor Novoa para la Presidencia de la Cámara, no lo hubiera dejado abandonado a su propia suerte. Sin embargo, en sus detalles adolecía, a mi juicio, de graves defectos, defectos que habría sido menester subsanar para garantizar la fortuna del nuevo establecimiento.

Era inconveniente, por ejemplo, imponer a todos los alumnos de la nueva escuela la obligación de estudiar todas las disciplinas que en ella habían de enseñar. Dado que ninguno podía ingresar sin ir premunido del diploma de bachiller en humanidades, era de suponer que todos habían adquirido de antemano en los liceos la ilustración general indispensable a cada profesor, y que solo les faltaría la instrucción especial que se ha menester para profesor una ciencia determinada.

Obligados a estudiar simultáneamente la historia, la filosofía, las matemáticas, las ciencias naturales, los aspirantes habrían adquirido una instrucción muy mediocre en cada uno de estos ramos y en ninguno la necesaria para encargarse de la enseñanza. Lo más conveniente era que en la escuela normal se concretaran a hacer estudios especiales de ciencia y de pedagogía.

En segundo lugar, no se podía anexar al Instituto Pedagógico al Instituto Nacional sin que el nuevo establecimiento desarbolase al antiguo, y sin que el antiguo contaminara con muchos de sus vicios al nuevo. 
Todos sabemos que si el número de alumnos del instituto nacional no excede anualmente de unos 1300, es porque el local no puede contener mayor número. Aplicar, entonces, a la escuela normal algunos de sus departamentos habría traído por consecuencia la reducción del número de alumnos que aprovechan la educación del Estado, la cual en Chile es sin disputa muy superior a la que se da en colegios particulares, ora con miras mercantiles, ora con fines sectarios.

Por otra parte, la enseñanza del Instituto Nacional adolecía en parte todavía de muchos de aquellos vicios que se quería extirpar al establecer la nueva institución. Aun cuando los profesores de aquel establecimiento se contaron siempre entre los más eximios profesores nacionales, sería cerrar los ojos a la evidencia el creer que la enseñanza que ellos daban con arreglo a los antiguos métodos habría podido servir de modelo a los nuevos aspirantes del magisterio docente. Si se instalaba el Instituto Pedagógico en el Instituto Nacional, no había más que un medio de evitar que los normalistas fuesen contagiados por los malos ejemplos y era el de poner a los pedagogos extranjeros en la odiodisísima situación de criticar a cada paso las formas didácticas empleadas por los profesores nacionales.

Aun suponiendo que la enseñanza del instituto nacional hubiese llegado en aquella época a ser realmente perfecta, convenía, en mi entender, reservar aquel grande establecimiento para instituir uno nuevo, con mejor organización, un cuerpo de repetidores destinados a llenar las vacantes de su profesorado.

Volviendo al proyecto del señor Domeyko, se fundarían allí diez becas de repetidores y se encargaría a un pedagogo la tarea de dirigirles en sus estudios y de ejercitarles en el arte de las enseñanzas. De esta manera, habría dos fuentes para la renovación del profesorado, se despertaría entre ambas una saludable emulación y se impediría que tarde o temprano sobreviniese el marasmo en el Instituto Nacional.

Yo me preparaba a formular estas y otras alegaciones por la prensa, sin perjuicio de aplaudir a la iniciativa tomada por el Gobierno, cuando la caída del Ministerio dejó fuera de discusión el proyecto de Escuela Normal de Profesores. Difícilmente podría apreciar el público cuanto se retarda y perturba la realización de las más suspiradas reformas por causa de los continuos cambios de Gabinete. De ordinario cuando el Presidente de la República no hace suyos los proyectos, los de cada Ministerio quedan abandonados a su propia suerte después de su caída. Fue lo que pasó al proyecto de fundación del Instituto Pedagógico: durante un año entero no se volvió a tratar del asunto ni en el seno del Gobierno ni en el seno del Consejo de Instrucción Pública.

\section{FUNDACIÓN DEL INSTITUTO PEDAGÓGICO}

A fines de 1887, se encontraba a cargo del Ministerio de Instrucción Pública el hoy finado don Pedro Lucio Cuadra. 
Todos conocemos las bellas prendas que adornaban a este distinguido ciudadano; y pocos ignoran que en el seno de las comisiones parlamentarias, se hacía notar por su excepcional competencia. Pero a la vez se sabe que por haber vivido consagrado de veinticinco años atrás a tareas bancarias y a estudios financieros, carecía de la preparación necesaria para dirigir el ramo de la instrucción pública. Estos antecedentes personales explican el hecho de que el señor Cuadra dejara relegados al más completo olvido los proyectos de reformas docentes.

Llamado en una ocasión a la sala de su despacho para tratar de un asunto particular, le hablé del atraso de la instrucción pública, de la falta de iniciativa particular para hacer mejoras y de la necesidad de que el Gobierno diera el impulso.

En particular, le propuse: $1^{\circ}$ que aprovechara la permanencia en Suiza y Alemania de varios profesores normalistas para ordenarles que se trasladaran a Suecia a seguir cursos de trabajos manuales; y $2^{\circ}$ que renovara el empeño del ministerio para fundar una Escuela Normal de Profesores.

El señor Cuadra, convino en todo conmigo, y aceptado estas ideas en general, me pidió que le llevara por escrito algunas indicaciones para hacer lo uno y lo otro.

En desempeño de este encargo, el 14 de noviembre presenté al Ministerio un memorándum, manifestándole la conveniencia y los medios de introducir los trabajos manuales entre los ramos de instrucción primaria: y el 2 de diciembre siguiente, le propuse unas bases para instituir un Seminario Pedagógico destinado a formar profesores de liceos. "mis más vivos deseos (le decía en la nota con la que las acompañé), mis más vivos deseos son que usted ponga pulso firme en la realización de aquel establecimiento. No veo obstáculo alguno de naturaleza insalvable que pudiera impedirla. Y entretanto, establecido el seminario, usted dejaría una obra duradera, de esas que los vientos no se llevan y cuyas incalculables consecuencias trascienden a todo el porvenir.

Presentados al Ministerio ambos proyectos, no supe yo de pronto qué suerte corrieron. Hasta hoy mismo ignoro si se ordenó la traslación a Nääs, en Suecia, de algunos de los preceptos que por disposición del Gobierno perfeccionaban sus estudios pedagógicos en Alemania (j). La inestabilidad de los Ministerios, a que hoy estamos habituados fue mal crónico del Gobierno de Balmaceda e interrumpía con suma frecuencia la prosecución de los planes de reformas administrativas. En estas condiciones, acaso no se habría renovado tan pronto el proyecto de fundar una escuela normal de profesores si una circunstancia casual no hubiera sobrevenido a ponerlo de nuevo en la orden del día.

A la vuelta de una nueva crisis, había sido encargado del Ministerio de instrucción pública, mi amigo Don Federico Puga Borne. Consagrada desde muy joven a las tareas del profesorado, primero en el Liceo de Valparaíso, más tarde en la Escuela de Medicina, conocí a fondo los vicios de la enseñanza pública; y tan pronto como 
asumió la dirección del servicio, se propuso reorganizarlo para mejorarlo. A su perseverante empeño se debe principalmente la aprobación por el Consejo de Instrucción Pública, del plan de estudios concéntricos que rigió en los liceos del Estado.

Un día (era el año de 1888) conversábamos en la sala de su despacho sobre la necesidad de la instrucción pública, e insensiblemente nos deslizamos a hablar del profesorado. Todas las reformas podían fracasar si para plantearlas no se contaba con un personal idóneo. Antes que a las leyes, la calidad de todo servicio público está subordinada a la competencia de los funcionarios respectivos. Particularmente en el servicio de instrucción, la buena enseñanza es fruto, menos de los planes de estudio que de las formas didácticas, o sea, de las aptitudes pedagogías del profesorado.

- Todos los vicios de nuestra enseñanza (me observó el señor Puga) proceden de la incompetencia de los profesores. Sin buen profesorado no podemos tener buenas enseñanzas. ¿Qué podríamos hacer para mejorarlo?

- Lo que se podría hacer (le contesté) es plantear el proyecto de un seminario pedagógico, que el año último propuse al ministerio.

El señor puga no tenía noticias de tal proyecto, lo pidió, se buscó y no se encontró. Por último, después de algunas averiguaciones, se supo que había sido pasado a manos de don Abelardo Núñez, Inspector General de Instrucción Primaria, para que dictaminara sobre las bases propuestas y no había sido devuelto al Ministerio a pesar de los largos meses transcurridos.

Recogido de manos del funcionario indicado, el señor Puga lo estudió, lo aprobó, lo modificó y lo hizo suyo. Dejó él subsistentes todas las bases orgánicas que yo había propuesto. El nuevo instituto debía tener existencia propia e independiente, si bien se le consideraría como una sección universitaria para los efectos de la clasificación de su profesorado. Se instalaría en él, además de los cursos y ejercicios de pedagogía, las cátedras necesarias para formar todos los profesores requeridos para el plan de estudios concéntricos.

No era posible aprovechar los cursos de la Universidad para preparar a los normalistas, por tres razones principales: $1^{\circ}$ porque allí no se enseñaban las humanidades; $2^{\circ}$ porque las ciencias no se enseñan lo mismo a quienes las estudian con fines profesionales y a quienes las estudian para profesarlas en seguida; y $3^{\circ}$ porque el profesorado universitario adolecía de muchos de los vicios que el nuevo instituto estaba destinado a extirpar. Se fundarían, pues, cursos especiales de lenguas, de matemáticas, de ciencias naturales, de historia y de pedagogía, cursos que durarían tres años.

Por último, el nuevo instituto quedaría sujeto al régimen del internado y constaría, como la Escuela Normal de París, de cierto número de becarios entre los más distinguidos: bachilleres en humanidades en todos los liceos. En cambio de 
las becas y pensiones que recibiría el Estado, ellos se comprometerían: $1^{\circ}$ a suplir gratuitamente a los profesores del Instituto Nacional y de los liceos de esta ciudad; $2^{\circ}$ desempeñar en las mismas condiciones los cargos administrativos subalternos del Instituto Pedagógico; y $3^{\circ}$ a servir durante nueve años en los liceos del Estado una vez que terminaran su preparación pedagógica.

En estos términos, la institución de las becas sería relativamente poco gravosa para el erario, y en cambio permitiría elegir el personal de aspirantes entre los alumnos de toda la República. Sin ellas, el Instituto Pedagógico serviría exclusivamente a los aspirantes de la capital; sería un instituto santiaguino, no un instituto que pudiera servir a toda la nación.

Acordadas las bases orgánicas, el señor Puga ordenó al Ministerio de Chile en Berlín, con fecha 25 de mayo de 1888, que contratara seis profesores alemanes de instrucción superior.

De una manera especial le recomendaba elegirlos entre aquellos que hubieran dado ya en la enseñanza pruebas prácticas de idoneidad y suficiencia; y para guardar la debida correlación con el plan de estudios secundarios, uno vendría a profesar la historia y la geografía, un segundo la filología, un tercero las matemáticas, un cuarto las ciencias físicas, un quinto las ciencias naturales y un sexto la pedagogía y la filosofía (k).

En estas circunstancias, cuando más empeñado estaba el ministerio en dar forma y vida al proyecto, una nueva crisis ministerial, ocasionada por la negativa del Consejo de Instrucción Pública a enviar comisiones examinadoras a los colegios particulares, fue causa de que la proyectada institución no naciera bajo el patrocinio del señor Puga.

Afortunadamente, en esta vez la crisis ministerial no interrumpió la realización del suspirado proyecto. A poco de instalados el nuevo Gabinete, empezaron a llegar los profesores contratados en Alemania, y fue menester proceder al planteamiento inmediato del instituto.

El nuevo Ministerio de Instrucción pública, que lo fue don Julio Bañados Espinoza, se encargó de la cartera con el propósito bien resuelto de reorganizar desde su fundamento la enseñanza nacional entera. Quizá sus ideas no estaban suficientemente maduradas; de cierto alguno de sus proyectos se resintieron de la juvenil precipitación con que fueron elaborados: y a mi juicio, habría tenido mejor suceso en sus empresas si hubiera gastado más prudencia en sus reformas. Con todo (debo rendir homenaje al adversario de 1891) nadie le negará el entusiasmo que puso al servicio de la enseñanza, la valentía con que proponía reformas, la actividad con que trataba de realizarlas, el espíritu liberal que le guiaba y la docilidad con que defería a los consejos e insinuaciones extrañas. 
En lo que toca al Instituto Pedagógico, al punto de encargarse de la cartera el señor Bañados hizo suyo el proyecto de su antecesor; pocos días después nos llamó a don Claudio Matte y a mí para discutir sus bases principales, y a las dos o tres conferencias, nos expresó que tenía ya los datos necesarios para organizar la nueva escuela.

En substancia, se conservarían las bases fundamentales que el señor Puga Borne se había propuesto dar a la institución. Se tomaría como modelo más bien la Escuela Normal Superior de París que los Seminarios de las universidades alemanas. La enseñanza sería absolutamente gratuita y se fundaría treinta becas para otros tantos aspirantes, que quedarían sujetos al régimen del internado. A cada becario se daría casa, comida y una pensión; en cambio todos quedarían sujetos a la obligación de prestar gratuitamente los servicios de suplentes y los de la administración subalterna antes enunciados.

Los profesores contratados tendrían a su cargo tanto la enseñanza como la vigilancia y educación de los aspirantes; y por último, para poder inscribirse como alumno del Instituto sería menester premunirse del diploma del bachiller en humanidades. Esta fue la única cortapisa que se puso, y ella era indispensable para garantizar la instrucción general de los aspirantes y para impedir que el profesorado malgastara en desarrollar sus conocimientos científicos un tiempo que convenía aplicar principalmente a desarrollar sus aptitudes pedagógicas.

Por lo que toca a la enseñanza del Instituto, ella se dividió en dos secciones, una de humanidades y otra de ciencias.

La de humanidades fue subdividida en cuatro cursos: el primero de castellano y latín, el segundo de francés y griego, el tercero de inglés y almena, y de historia y geografía el cuarto.

Análogamente, la sección de ciencias se subdividió en dos cursos, uno de matemáticas y otro de ciencias naturales.

Cada curso duraría a lo menos tres años, y se podría prolongarlo facultativamente por un semestre.

Por último, se confirió al cuerpo de profesores la facultad de proponer al Consejo de Instrucción Pública el plan de estudios del nuevo Instituto. Fue esta disposición muy discreta, porque solo ellos podían apreciar el grado de preparación científica con que iban a ingresar los aspirantes y, por tanto, la posibilidad de aplicar más o menos tiempo a la preparación pedagógica.

Tales fueron las disposiciones fundamentales del estatuto orgánico dictado por el Gobierno el 29 de abril de 1889 para crear el Instituto Pedagógico.

En desempeño de una atribución, que a la vez era una obligación, el cuerpo de profesores presentó un proyecto de plan de estudios a mediados de junio de 1889, y acto continuo el Consejo pidió informe a la Facultad de filosofía y Humanidades. 
Fuese por causa de la novedad de la institución, fuese por causa de la desconfianza con que muchos recibían las obras de gobierno de Balmaceda, la Facultad no se dio prisa para expedir su dictamen; y trascurrían los días, las semanas y los meses, sin que se pudiera organizar definitivamente la enseñanza pedagógica, porque ella no cumplía con aquel trámite legal.

En realidad de verdad, la fundación de la nueva escuela fue entorpecida a los principios muchos más por la existencia pasiva de la rutina que por el ataque activo del clericalismo.

Para todos los que estaban connaturalizados con las antiguas prácticas, el Instituto pedagógico iba a introducir en la enseñanza nacional novedades peligrosas a lo menos de éxito inseguro. En particular se hacían notar a la cabeza de esta resistencia inerte algunos de los profesores más distinguidos del antiguo régimen, sobre todo aquellos que por su edad no estaban en situación de ponerse a estudiar de nuevo para reformar sus enseñanzas. El hecho público y notorio de que la aplicación inicial del plan de estudios céntricos se retardara en el Instituto Nacional durante tres años, es indicio de los grandes obstáculos que el consejo de instrucción pública hubo de vencer para realizar las reformas. Como era de presumirlo, la facultad de Filosofías y Humanidades se sentía influenciada y arredrada por la actitud hostil de profesores a quienes todos los chilenos debemos afecto y respeto.

Por último, a fines del mes de junio de 1890, o sea un año después de requerida, la Facultad presentó su informe al Consejo, sin emitir opinión alguna sobre la fundación del Instituto Pedagógico, manifestaba extrañeza de que se le hubiera pedido dictamen sobre un plan de estudio de una escuela cuya existencia legal no le constaba.

Comoquiera que el Consejo no debe cuenta de sus actos a las Facultades, juzgo inoficioso contestar en este punto a la de Humanidades; pero acaso habría sido preferible que lo hiciera, tanto por cortesía cuanto para afianzar la existencia de la nueva escuela, o sea, para matar en germen la idea propalada más tarde de su ilegalidad.

En efecto, personas que parecen ignorar tanto nuestra historia constitucional cuanto los antecedentes de la nueva escuela superior de pedagogía, han tachado la legalidad de su institución porque la suponen obra de un simple decreto gubernativo. Si la creación de empleos (dicen) es incumbencia exclusiva del legislador, el Instituto Pedagógico no se ha podido fundar por un acto de mera administración.

Esa es la verdad: pero también lo es que una ley, la ley de presupuesto, con cuya autorización se ha establecido originariamente en Chile casi todos los servicios públicos, había facultado al Gobierno reiteradas veces para fundar el establecimiento indicado. No se juzgará inoportuno recordar estos antecedentes. 
Por primera vez, aparece consultado un ítem para fundar una escuela normal de profesores en los presupuestos de 1887. Ascendente a la suma de veinte mil pesos, este ítem fue apuntado en la comisión de presupuestos a indicación de Don Pedro Montt, y fue aprobado en seguida por unanimidad en el Senado y con un solo voto adverso en la Cámara de Diputados. Al año siguiente de 1888, se renovó sin discusión, y al subsiguiente de 1889 se elevó a cuarenta mil pesos, por indicación del ministerio. En los tres años se consultó el ítem a iniciativa del Gobierno, quien expuso las tres veces que lo pedía con el objeto determinado de fundar una escuela de preparación pedagógica para el profesorado de instrucción secundaria. La glosa misma así lo manifiesta. Ahora bien, mientras no se demuestre que estas autorizaciones legislativas, reiteradas en tres años consecutivos, adolecen de algún vicio, puedo declarar que la existencia del Instituto Pedagógico descansa en bases de estricta legalidad.

No tienen mejor origen otros servicios e instituciones públicas. Los correos, los telégrafos, los ferrocarriles, el antiguo cuerpo de ingenieros civiles, la primitiva oficina de estadística, la oficina de hidrográfica, la delegación fiscal de salitreras, el consejo superior de higiene, todo el servicio de instrucción pública, etc., se han instituido originariamente en la misma afirma y sin protestas de los poderes fiscalizadores del Estado. Sin duda, muchas ilegalidades cometidas antes, no autorizan a cometer una nueva ahora; pero una práctica de derecho público, no puede ser seguida durante tan largo tiempo por todos los gobiernos y por todos los partidos si no guarda rigurosa conformidad con la Constitución política, porque la ley no es lo que reza su letra, es lo que reza su interpretación.

En estas condiciones se fundó el Instituto Pedagógico, y dado caso que al fundarlo se hubiera incurrido en algunas ilegalidad, ella estaría tres y más veces subsanada por el hecho de haberse consultado de 1890 adelante las sumas necesarias para cubrir los sueldos y demás gastos del establecimiento.

En mi sentir, lo único que hubo de irregular, no de ilegal, en su fundación, fue que se le instituyera sin previa anuencia y acuerdo del consejo de instrucción pública. Al consejo mismo le llamó la atención esta especie de desaire.

¿Se pretendía acaso dejar bajo la mano del Gobierno una escuela que, por naturaleza de su enseñanza, debe estar sometida a la jurisdicción del consejo? Para no resolver sin estudio punto de suyo tan grave, en la sesión del 17 de junio de 1889 se encargó a don Pedro Montt, que dictaminara acerca de la condición jurídica de la nueva escuela.

El señor Montt presentó su dictamen el 8 de julio siguiente y en él demostraba que el Instituto Pedagógico es un establecimiento de instrucción universitaria, y que por lo tanto, debe estar sometido a la autoridad del consejo y sus profesores se deben considerar como miembros docentes de las respetivas facultades. En conformidad 
con las conclusiones de este dictamen, el consejo declaró el 13 de enero de 1890, que la nueva escuela debe estar bajo su mano, y el 30 de junio siguiente, que ella es un establecimiento de instrucción superior y que, por tanto, sus profesores forman parte de la universidad en calidad de miembros docentes.

Si se exceptúa la última declaración, la del 30 de junio de 1890, la facultad de filosofía y humanidades conocía, porque eran públicos, todos los antecedentes legales de la fundación del Instituto Pedagógico. ¿Cómo se explica, entonces, que en su informe fingiera ignorarlos absolutamente?

La segunda y última objeción que la facultad representó en su informe fue, si cabe, más peregrina. Después de haber examinado el plan de estudios, al revés y al derecho, durante un año cabal, la facultad informante no le encontró más que un solo punto negro, el de no aparecer allí ni la psicología subjetiva, ni la metafísica, ni la teodiceal. Tal fue en substancia el informe de la facultad, informe que retardó un año entero la aprobación del plan de estudios, sin que este retardo fuese compensado por indicación alguna de utilidad.

En el ínterin, esto es, mientras la facultad meditaba reposadamente su contestación, el consejo de instrucción pública se había cansado de aguardarla; y para anticipar su trabajo, había encargado a una comisión especial que estudiara y revisara el proyecto aludido, sin perjuicio de tomar a su tiempo en consideración las observaciones que la facultad se dignara hacerle.

Compuesta dicha comisión de los señores Bañados, Hanssen, Hurtado, Johow, Lilienthal y el infraescrito, procedió con toda diligencia a desempeñar su tarea, y en la sesión del 28 de abril de 1890 presentó al consejo el plan de estudios en la forma en que ella lo había aprobado.

La única modificación de importancia que había introducido la comisión había sido la de eliminar el plan de estudios pedagógicos la teodicea y la metafísica, porque suprimidos estos ramos desde 1889 en la instrucción secundaria con el objeto de limpiar de impurezas a la enseñanza científica, no había para qué exigir su conocimiento de parte de los aspirantes al profesorado.

El consejo, empero, no pensó de la misma manera; y si mal no recuerdo, a indicación del señor Hurtado, acordó el 23 de junio, o sea una semana antes de que la facultad lo pidiera, restablecer el estudio de ambos ramos en los cursos de Instituto Pedagógico.

Mientras el consejo apresuraba en lo posible la organización de la enseñanza de la nueva escuela, el ministerio no desatendía la tarea propiamente administrativa.

Habían ya llegado a Chile todos los pedagogos contratados en Alemania, y era urgente proceder a la instalación del nuevo instituto.

Con su característica diligencia, el ministro Bañados tomó en arriendo la casa número 178 de la calle de Las Delicias, por el canon anual de cinco mil pesos, 
adquiero el mobiliario indispensable y pidió a Europa una gran cantidad de instrumentos y útiles para la enseñanza objetiva.

Por desgracia, incurrió en dos errores cuyas consecuencias han servido de pretexto a muchos de los ataques que se han dirigido contra el nuevo establecimiento.

Fue el primero el haber dispuesto inconsultamente que no se admitieran más alumnos hasta que los del primer curso terminaran sus estudios. Dadas la escasez de aspirantes competentes y la gravedad de las reformas que se habían acometido en la enseñanza secundaria, lo más cuerdo habría sido admitir 25 o 30 alumnos en cada año. Con esta medida, el Estado no habría aumentado sus gastos, habría aprovechado mejor los servicios de los profesores alemanes, y habría provisto de personal idóneo, en muchos menos tiempo, a todos los liceos públicos, y en seguida a todos los colegios particulares.

El segundo error fue el de haber establecido innecesariamente una administración rumbosa, creando varios empleos subalternos de que se habría podido prescindir con ventaja.

Cuando los que habíamos promovido la fundación del Instituto Pedagógico, insinuamos en que se diera beca y expansión a cada aspirante, manifestábamos que estos desembolsos del Erario se podrían compensar en gran parte exigiendo a los normalistas ciertos servicios gratuitos, y entre estos servicios enumerábamos expresamente los de escribientes, ecónomos, tesoreros, inspectores y otros del mismo establecimiento. Pero no se hizo así, por desgracia.

Los dos errores apuntados han sido causa directa de que haya ascendido a una suma enorme el costo de la educación por cabeza, y de que los profesores aparezcan gozando de remuneraciones poco proporcionadas a los resultados obtenidos. Algunos, aun, que no aceptan más instrucción que la instrucción a bon marché, y que están muy satisfechos de que se mantenga el profesorado nacional con raciones de hambre, se han preguntado si valía la pena sostener por más tiempo un establecimiento tan dispendioso.

Prescindiendo de estos errores, que con mejor acuerdo se habrían podido evitar, la nueva institución se planteó sin mayores tropiezos bajo la inmediata dirección de don Federico Johow.

Se empezó entonces a recluir normalistas entre los aspirantes de todas las provincias, y en agosto del mismo año 1889, se instalaba el Instituto provisionalmente, para el efecto de elegir entre los inscritos los 30 en calidad de becarios debían consagrarse a los estudio pedagógicos.

Es sabido que de los numerosos jóvenes que en 1889 se matricularon como aspirantes externos, no permanecieron en el instituto más de cuatro, todos los demás se desbandaron, arrendados por la seriedad de los estudios, o desalentados por la falta de alicientes del profesorado, o contados en su carrera por la escasez de 
recursos. Sin la fundación tan combatida de las becas, acaso el Instituto Pedagógico habría tenido que cerrar sus puertas por falta de alumnos y no habría alcanzado a dar frutos que permitieran apreciar la utilidad de su creación.

Hecha la selección, la escuela normalizó sus cursos desde el mes de abril de 1890 y después de tres años de enseñanza acaba de terminar en estos días (noviembre de 1892) la preparación pedagógica de 28 o 30 aspirantes. El grado en que ellos hayan aprovechado esta enseñanza, nos lo dirá el porvenir.

De acierto con que obren y la idoneidad que manifiesten dependen en mucha parte del prestigio y la existencia del nuevo instituto. Tal es la historia auténtica del Instituto Pedagógico, referida a la luz de documentos públicos y completada con algunos datos personales.

Es muy probable que en su organización hayan tenido mayor intervención algunas de las personas que he citado. También lo es que hayan intervenido algunas otras que no he mencionado.

En todo aquello que no consta oficialmente, he querido ceñirme a lo que me consta personalmente, por manera que no temo se me hagan rectificaciones de importancia, aun cuando quede esperando que otros completen la relación precedente.

De los datos apuntados se infiere que la necesidad de una escuela superior de pedagogía se sentía por nuestros educacionistas desde ha cincuenta años, que su fundación fue obra colectiva de muchos ciudadanos distinguidos, y en fin, que nuestro magnífico Instituto Pedagógico no nació como obra de partido o de guerra, sino como obra nacional, indispensable para extirpar de nuestros liceos las prácticas inveteradas de la enseñanza mecánica. 